\title{
Modernity and English mixing: A study of Nepali television commercials ${ }^{1}$
}

-- Khagendra Acharya

In this paper, I investigate the issue of English mixing in Nepali television commercials. More specifically, based on qualitative data taken from a total of four hours of Nepali TV commercials broadcasted on the major Nepali television stations - Avenues Television and Kantipur Television from $7 \mathrm{am}$ to $9 \mathrm{am}$ and $7 \mathrm{pm}$ to $9 \mathrm{pm}$ since 1 July to 1 October 2009 , I examine the motivations for English mixing in Nepali TV commercials. For the analysis, primarily I categorize them into two major types, Nepali-only (NO) and English mixed (EM). NO includes commercials aired in Nepali only and EM includes advertisements aired in Nepali in juxtaposition with English. After it, I study the differences between EM and NO as the dichotomous treatment of NO and EM is critical in examining the purpose of English-mixing. The findings suggest that English-mixing in Nepalese TV commercials is a carefully constructed exemplar of the marketing of modernity.

Though the issue of modernity invokes geographical, sociopolitical, cultural and other concerns and emerges with the notions of alternative modernity (Appadurai, 1996; Gaonkar, 1999), "an ethnocentric prison" (Taylor, 1995, p. 28), "Ethnocentric diffusionist ideology" (Friedman, 2006, p. 429) and so forth, a very strong paradigm in modernity is a linear model. In this model, "[modernity] cut across all boundaries of geography and ethnicity, of class and nationality, of religion and ideology: in this sense, modernity can be said to unite all mankind (Berman, 1983, p. 15)". Of such uniting factors one of the most influencial is the use of English language. In a sense, English use in any discourse signifies orientation of non-

${ }^{1}$ The article is based on presentation prepared for an International Workshop on Media Strategies for Social Change held in Haifa, Israel from 18-30 October 2009. I acknowledge Jamie Shinhee Lee for his insights.

Bodhi, 3 (1), 53-60. ISSN 2091-0479. (C) 2009 Kathmandu University 
western traditional society's population towards westernization and thus modernity.

English-mixing in Nepali TV commercials is very significant. The proportion of Nepali-only (NO) versus English-mixing (EM) in the corpus of commercials is summarized below. Figure 1 shows the quantity of EM commercial slightly higher than that of NO.

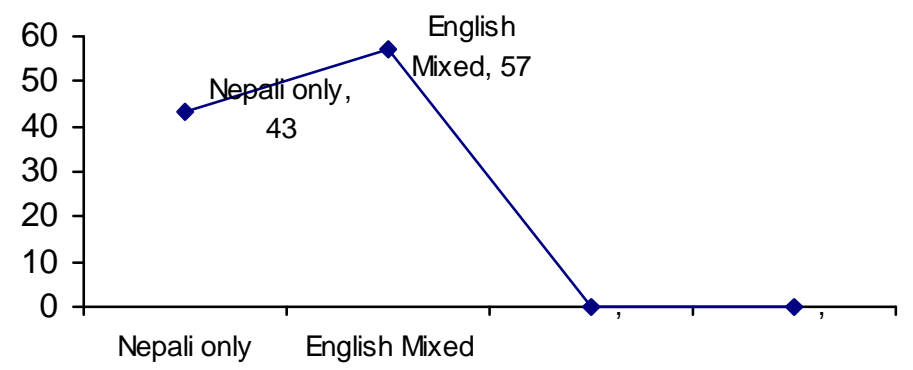

Figure 1: Proportion of $N O$ and EM in Nepali TV commercials

Figure 2 presents the top four products advertised in the NO category. Advertisements of Construction items count the highest followed by the advertisements of oil/ghee, rice/flour and land.

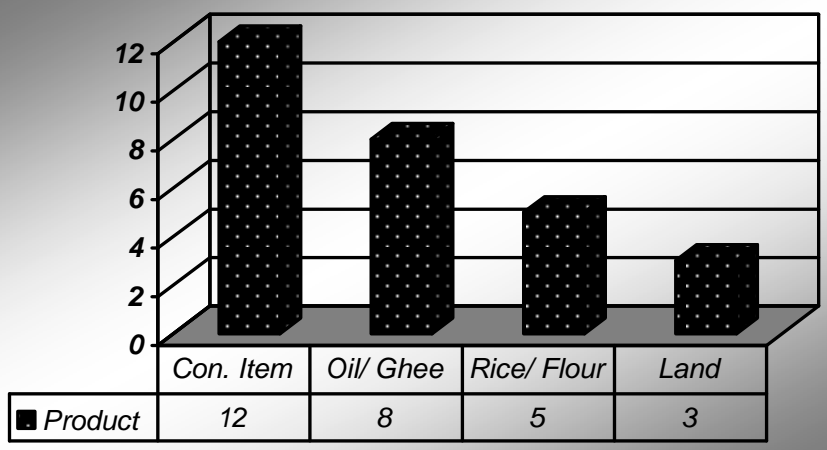

Figure 2: Top four products advertised in NO commercials

Bodhi, 3 (1), 53-60. ISSN 2091-0479. (C) 2009 Kathmandu University 
The top four products advertised in the EM category, shown in Figure 3, demonstrate an order different from that of those in NO. As the figure shows, convenient foods are mostly advertised with English-mixing.

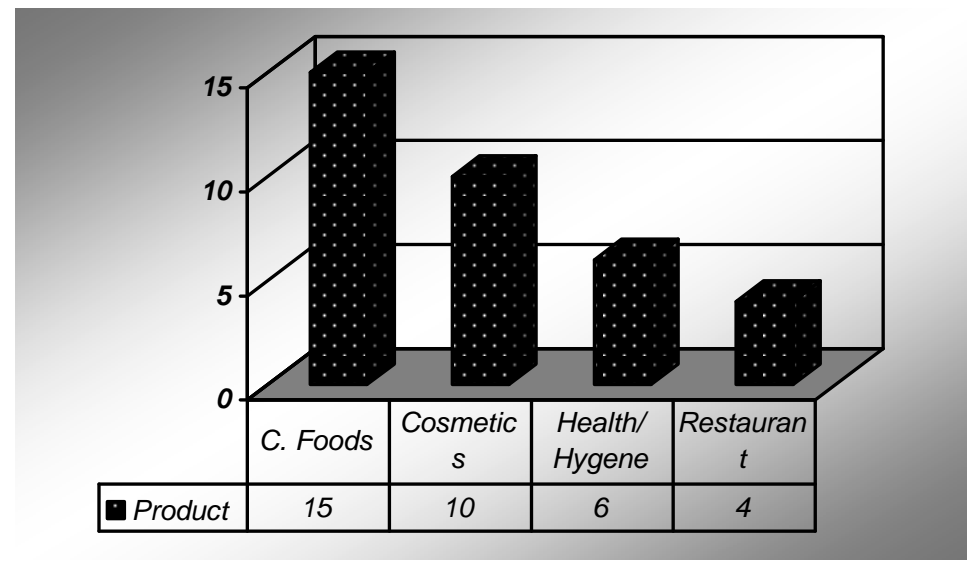

Figure 3: Top four products advertised in EM commercials

In order to establish a connection between English mixing and its role in promoting and reinforcing modernity in TV commercials, it is necessary to examine how EM commercials differ from NO commercials. So, I discuss commercials in EM in contrast with those in NO in terms of featured identities ${ }^{2}$ and endorsed messages.

What is found is that addressees for NO commercials differ from those for EM commercials. The former target the consumers, who are archetypic traditional characters like housewives. Similarly, whenever Nepal and Nepali nationalism is to be evoked; especially in nonprofit, public announcementtype advertisements, only Nepali is used. Another issue that appears significant is age - it appears to be a critical variable in language use patterns in TV advertisements. When commercials

2 Featured identities refers to the characters presented in the advertisements with whom the targeted audiences are meant to identify themselves with.

Bodhi, 3 (1), 53-60. ISSN 2091-0479. (C) 2009 Kathmandu University 
cater to older generations, Nepali is used, whereas when commercials are geared toward younger generations, English is usually mixed with Nepali. In a sense, Nepali is not expected to be used dominantly in commercials for the new generation. Similarly, English is not expected to be used even sporadically in commercials for the older generation.

The dichotomy of EM and NO is also visible in terms of products. There are certain categories of products which are advertised in Nepali-only. First, there are construction items (e.g. cement and iron), and second there are ingredients for preparing Nepali food (e.g. rice and oil). In contrast, there are products which are advertised in English to demonstrate what modernity is intended to mean. First, it means having the younger generations' ethics of leisure time activities especially entertainment. Second, modernity means that people care about product packaging as much as they care about functions. Third, anything high-tech, fast, and efficient is modern. Fourth, being rebellious, edgy, and unique are typical characteristics of modern youthfulness featured in EM commercials.

The following section will empirically discuss the linguistic construction of modernity in Nepali TV commercials. I begin with some commercials related to apparel. In this domain, there are commercials about clothes and jewels. In these commercials contrasts between traditional and modern, and old and young are clearly represented. Each of these dichotomies is correlated with the presence or absence of English use. A case in point appears in two different advertisements of Riddi Siddi Jewellers. The name of the shop - Riddi-Siddi - is traditional; Riddi and Siddi are the names from Hindu myths representing loyal wives. The first commercial advertises jewels specially designed for married women and housewives. In the commercial which is advertised in Nepali-only, the main character featured is a middle aged housewife who is preparing to go to Jewels shop. The husband, who sees her doing it asks her what she is doing to which she responds, "Riddi-Siddi Jewelers ma jana lageko ni" (going to Riddi-Siddi Jewellers).

Bodhi, 3 (1), 53-60. ISSN 2091-0479. (C) 2009 Kathmandu University 
The ad features absence of English and adheres to archetypal codes of traditions. In contrast, the second ad when advertises targeting young women, it uses English. This ad presents a newly married wife complaining her husband about his negligence. She complains that he does not care about her jewels to which he responds, "ma lai ke thaha aadhunik sunko gahana kaha payienchha bhanera" (how do I know where the modern jewels can be found). Another character, who happens to arrive there, informs them that the modern jewels are available in Riddi-Siddi. In the end i.e. after they purchase jewels, the wife tells her husband, "Thank you". These two commercials though they advertise the same shop show that Nepali is associated with middle-aged people who have traditional mind set, whereas English is associated with younger people who are up-to-date with the changing fashion.

The three-way correlation among English, modernity, and youth is best exemplified in another commercial. A young man (late Indra Lohani) in a suit appears in a chamber doing his official work. Meantime, the voiceover speaks, "professional, strong, proud, scientific, bold, confident, classy, pioneer." The whole series of words in English is followed by the visual of shoes along with the brand in Nepali. The use of English is preferred here in the commercial to target young office goers who are already in the process of modernization. Another case in point is TV commercials of restaurants. The commercial of Roast Duck Chinese Restaurant shifts its camera focus from location to location while the voiceover describes the characteristics, "looking for some best Chinese restaurant...." This alliance between English mixing and younger generations is also present in education consultancy's commercials. For instance, the commercial of Alfa Beta, which is meant for young students, advertises entirely in English. The image in the ad appeals to the majority of young people's craze for abroad studies.

Other commercial that illustrates correlation of absence or presence of English and modernity is health and hygiene

Bodhi, 3 (1), 53-60. ISSN 2091-0479. (C) 2009 Kathmandu University 
products. In particular, the way that the contemporary notion of hygiene in EM commercials is catered supports the claim that English use is linked to modernity. I will now contrast how health and hygiene images are presented in NO commercials with those in EM. Advertisements of mustard oil and snacks are the cases in point. The first commercial i.e. of Family mustard oil is in Nepali, with no trace of English whereas the second one mixes English. In the first one, a joint family is being served by daughter-in-law. All the family members happily enjoy the food and the voiceover gives credit "for such item" to "Family Tori ko Tel". This commercial demonstrates that anything traditionally identifiable as Nepali is advertised in Nepali. The second one, which is of "Kurmure" snacks, uses English in conjunction with Nepali. The setting is of a restaurant where a boy and a girl dance salsa. The song that is played to guide their dance uses both English and Nepali. After the dance, voiceover says, "Kurmure break".

In the EM commercials of health and hygiene, it is interesting to note the redefined roles of women and men. The EM commercials in my study seem to project the images of sexuality and beauty differently. In the commercial of Colgate Tooth Paste, the role of women is seen different from traditional domesticity into career-oriented modernity. The woman in this commercial is dressed in white with stethoscope round her neck. Posed as a doctor she narrates the advice that she had given to her son. The commercial conveys the identity of a sophisticated career woman, still taking responsibility of looking after her children. Here, English mixing is used as a linguistic strategy to present modern Nepali woman's demand for lifestyle changes through the use of modern technology.

The conclusion that EM advertisements are linked with modern Nepali women's identities find further support from another ad for $\mathrm{U}$ and $\mathrm{Me}$ Cheese balls. In this ad, an attractive young Nepali woman in a crowd coxes a man. The characteristics of the woman featured in this EM commercial are once again those of a modern woman who takes initiative in pursuing her

Bodhi, 3 (1), 53-60. ISSN 2091-0479. (C) 2009 Kathmandu University 
love interest, knows what she wants, and pursues with confidence.

When the EM advertisements feature male, there is again the role reversal, not an adherence to the traditional masculinity. When young, urban, single males are featured in the EM commercials, they are often characterized as "metrosexual". These metrosexuals readily participate in a discourse that is traditionally classified as within the female domain of interest, such as skin care. The ad of Imami Fair and Handsome Cream is a case in point. In the commercial, a man who is accused of using his sister's cream is advised by another male not to use women's cream. After the advice, the male is shown with improved appearance - much white and with lovely cheeks. At the end of the ad, he is admired by some beautiful girls saying, "hi handsome". This ad demonstrates that typically femaleoriented consumer culture, such as putting on makeup, is no longer identified as exclusively female. The blurring of boundary is definitely a marker of modernity.

The third domain in which NO and EM commercials contrast in terms of expressing modernity or the lack of it is that of construction items. I will show evidence that EM represents modern technology, whereas NO does to the traditional one. For instance the ad of RMC Jasta Pata contains only Nepali. In this ad two dancers advise an olderly man who is unable to decide which jasta pata to use through a song, "Ye dai, Ghar Chhauna lai/ Samjhanus hai RMC jasta pata lai" (Hello elder brother, remember RMC zinc sheet to cover the roof). On the other hand, the ad of Safe Crete - a modern product for making the construction strong - uses English mixing. It shows that the linguistic strategy of selecting either EM or NO depends on the products advertised and the identities presented in each commercial.

The analysis of Nepali-only and English-mixing commercials in advertising reveals that there is a predictable correlation between English-mixing and modernity. English-mixing is used

Bodhi, 3 (1), 53-60. ISSN 2091-0479. (C) 2009 Kathmandu University 
to indicate younger generations' modern identities, whereas the exclusive use of Nepali signifies older generations' traditional identities. To conclude, constructing language-code dichotomy of "traditional" versus "modern," and "old" versus "young" English mixed commercials construct and reinforce modernity.

\section{References}

Appadurai, A. (1996). Modernity at large: Cultural dimensions of globalization. Minneapolis: U of Minesota P.

Berman, M. (1983). All that is solid melts into air: The experience of modernity. UK: Verso.

Friedman, S. S. (2006). Periodizing modernism: Postcolonial modernities and the space/ time borders of modernist studies. Modernism/ Modernity, 13 (3), 425-443.

Gaonkar, D. P. (1999). On alternative modernaties. Public Culture, 11 (1), 1-18.

Taylor, C. (1995). Two theories of modernity. Hasting Center Report, 25 (2), 24-33.

Bodhi, 3 (1), 53-60. ISSN 2091-0479. (C) 2009 Kathmandu University 